\title{
Exploration of Higher Vocational Logistics Teaching Mode Based on the Modern Education Technology
}

\author{
Ya-Feng GUAN ${ }^{1, a}$ \\ ${ }^{1}$ Chongqing College of electronic engineering, Chongqing, 401331, China \\ aGyf-513@163.com
}

\begin{abstract}
Keywords: Modern education technology, Higher vocational logistics teaching, Application, Problems and solutions.
\end{abstract}

\begin{abstract}
This paper explains the means and effects of teaching by modern educational technology in higher vocational logistics According to The characteristics of Logistics Course teaching, several information technology are used. Obviously, the ability to adapt of Graduates is more and more enhanced, and they can meet the requirements of enterprises now.
\end{abstract}

\section{The connotation of modern educational technology}

Modern educational technology is an emerging interdisciplinary discipline. With the development of information technology; modern information technology is applied to higher vocational education teaching. It is specifically defined as: the theory and practice of using of education theory and modern information technology through the design, development, utilization, evaluation and management of the teaching process and teaching resources, to achieve optimal teaching effect.

The emphases of this paper are on the modern educational technology's influence on continuing education and its innovation. The process of the application of modern educational technology is using of modern technology to conduct a comprehensive integration of the teaching field, in order to achieve the best teaching effect, and promote the process of learners get better development guiding by the modern educational theory .

According to the connotation of the modern education technology it can be understood as two aspects of "the modern educational technology" and "technology of modern education".

"The modern educational technology" relates to hardware and software which are widely used in the teaching field, including educational information communication and transmission technology, storage and retrieval technology, processing technology, display and copy technology etc. Using the educational technology, all means of expression can be realized such as text, image, sound, video, animation. Comprehensive application of the advanced educational technology can realize text, image, sound, video, animation and other means of expression, which make the logistics theory teaching full of picture, sound, and mobilize students' visual and auditory, form a variety of external stimuli. So that it creates a rich and colorful, vivid teaching situation and achieve the best teaching effect.

"Technology of modern education" refers to the application in the educational field of new technology, new equipment which generated along with the development of modern society, so that the graduates can adapt to industry and be satisfied with the requirements of social development. Such as the Application of logistics automatic identification technology (bar code, RFID, EPC), EDI, GPS/GIS technology, automatic sorting technology is the trend of modern logistics enter prises in the future development, but also is indispensable construction project of the logistics lab construction. Therefore, the construction of logistics training room should emphasis "the application of modern education technology", namely the application of new technology in the modern logistics industry.

The urgency of the application of modern educational technology in Higher Vocational Logistics Teaching

\section{The characteristics of Logistics Course Teaching in Higher Vocational Education}

The author is engaged in logistics teaching has been nearly 5 years, from the practical experience 
of teaching of logistics, there are great difference between the logistics teaching and the other courses, its main characteristics are the following four aspects:

(1) Professional.

In the teaching process, many professional terms related to the theory and the unique logistics facilities should be explained, such as 3PL, VMI, QR, SCM, JIT, container and so on.

(2) Boring and abstract.

Although the perceptual knowledge can be understood by observing the daily life, but its theoretical difficulty is beyond the capacity of most students, especially about economics and management theory, such as Pareto's law, MRP, ERP, Saving algorithm etc.. Mathematical knowledge involved in operations research, such as calculus, it is more difficult to master.

(3) Practical.

Logistics is the operational management activities, it requires practitioners not only master the theory and method of logistics management, but also need to have some practical experience and strong practical ability to handle and solve the actual problems in the job site work. For example "goods storage and distribution", "purchasing organization and implementation", "international freight forwarders", these courses contain both strong professional and technical knowledge.

(4)Comprehensive.

Logistics application extensively, involving government, transportation industry, the financial industry, warehousing industry, communication industry, retail trade, customs, industry and commerce, taxation and individuals, using knowledge of the economics, management science, sociology, machinery, physics, computer science .In conclusion, logistics management courses is an Integration of operations research, engineering, systems engineering, computer and network, project management disciplines and so on.

\section{The urgency of optimize logistics teaching reality using modern educational technology}

Application of modern educational technology, creating of situational teaching.

(1)Due to the abstraction of logistics concept, if only teachers explain the logistic processes such as storage, handling, inventory, sorting, distribution by the traditional teaching means, students could not understand it well. In fact, now, students use and practice software and hardware facilities such as WMS, forklifts, pallet, bar code recognition technology, electronic labeling picking, They are like enterprise workers, practice makes perfect!

(2) Inspired the learning interest with modern education technology

"Interest is the best teacher." the traditional logistics teaching is relatively dull, which result in some students are not interested in the logistics course, and disperse the attention of students, the teaching effect is not ideal.

Now, different teaching means (through the text, animation, and physical sand table and role play simulation) stimulate the senses of students from the visual, auditory, tactile and other aspects, which make the realization of information transmission diversity. So, it attract the attention of students and stimulate the learning interest, to change students from be passive to be active.

(3) Improving students 'skills through modern education technology.

Due to various reasons, now logistics teaching in our country is still in the theoretical teaching, practical teaching can not be guaranteed, students learn just "theory of knowledge", so their ability and skill is weak. Using modern education technology to create the logistics training center, which solve the problem of operation in traditional logistics teaching, let the students learn by doing, so that it is conducive to the completion of the practical teaching objectives

(4)Cultivated the sense of participation with modern education technology

The traditional teaching way is single and passive, which is lack of opportunities such as independent exploration, cooperation, independently acquisition. The uses of modern network technology create an open learning environment, and the learning process is interactive between students and teachers. The network resources provided by the school, under the guidance of the teacher, students can independently find logistics knowledge, or Make Movie, PPT, video even edit graphics. THE integration of educational information resources is enabling to make fun of 
students in learning.

\section{The application and its effect of modern education technology in Logistics major in Higher Vocational Education}

To change the traditional teaching means, in addition to make full use of the computer and multimedia assisted teaching tools, such as PPT, video and animation demonstration, according to the characteristics of logistics course in higher vocational education, more modern education technology is introduced to optimize the logistics teaching.

\section{Virtual reality technologies}

ERP sand table and logistics sand table are used in Practical training in the logistics major. Sand table is a kind of information technology software; it is actual combat simulation in the enterprise daily operation through the establishment of virtual model. By this way, graduates can not only master the professional logistics theory, but also can get the actual operation experience in logistics. We have developed sand table teaching courses for several years, formed a set of mature teaching methods and accumulated rich experience in teaching. The students repeated success in all kinds of sand in the competition

Taking ERP sand table for example, ERP sand table is shout for enterprise resources planning sand table, its the basic idea is considered manufacturing process as a closely related to the "supply chain" -- from the supplier, manufacturing plants, distribution network to the customer. The physical sand table intuitionist and visual display the internal and external resources of corporate: including workshop, equipment, materials, human resources, capital, information, even including suppliers and customers. As an enterprise supply chain management actual combat drilling simulation teaching method, ERP sand table reference to the enterprise management of the actual situation, design the important role of the supply chain for students, for example suppliers at all levels, the R \& D department, production department, sales department, logistics department and market department. So Students experience the whole process of supply chain management in the enterprise. To experiential interactive learning method, melting role plays, case analysis and expert diagnosis, sand table teaching Let the students study in participating, and growth in the failure and success of various decision.

ERP sand table is a first course in freshman entrance, which let the students play different roles in the supply chain. They should think about questions when they manage the company: how to ensure that business decision correct and Effective; how to control costs to maximize the gains; how to make product strategy and arrangement research and development according to the market prospects; how to keep the balance between shortage and overstock; how to meet the changing market demands to be Competitive; how to obtain market information to realize the competitive advantage of the enterprise etc.. So, Students achieve "logistics early experience," and go into learn professional course in the next three years with all kinds of problems and curiosity.

Application of the virtual reality technology like ERP sand table has changed the traditional teaching mode of "teachers say and students listen". The simulation teaching method has the following characteristics: firstly, direct --students may understand the nature of business through the result of management in course. Second: attempt-- student confirm their own ideas in simulation corporation management and directly see the results. Third, vivid -- dull course become lively and interesting, students would like participate in it.

\section{Modern logistics technology}

In the "goods storage and distribution" course which is based on the working process, advanced logistics technology (such as modern warehousing, handling technology, RF and bar code technology, and electronic sorting technology) is used and docked with WMS. students in group finish work, including goods inbound, handling, storage, processing, sorting, outbound operations, System integration realize the allocation and integration of the resources of the business flow, logistics, goods and information flow, which is making the full realization of modern vocational 
education pattern--Integration of teaching, learning, doing.

The optimization of logistics teaching by using modern logistics technology can improve the practical ability of students; cultivate skills talents who are expected by enterprise. In recent three years, graduates employment rate reached $96.41 \%$ in our institution, professional counterparts rate was $97.86 \%$. The high evaluation of the graduates got from the employing units, reaching more than $90 \%$, good rate of more than $85 \%$.

\section{The modern information technology}

In order to cultivate the students' basic skills in different professional direction, we have purchased a variety of information systems for logistics professional core courses such as ERP system, supply chain management, transportation management optimization software, logistics cost management software, 3D international customs system, logistics route planning system, international freight forwarders and international trade settlement system and so on. In the "distribution center planning" course, RaLc simulation software is used. It integrates modern logistics technology, artificial intelligence, 3D image, data processing and computer simulation technology as whole software, which is a simulation software system in Professional logistics field. The existing or planned logistics distribution center or factory can be built with a virtual model 3D animation model in the computer. Taking the 3D animation as the carrier, system simulation platforms are integrated by operator, handling equipment, goods, control system, data information. 3D animation model is specific, image, vivid, and display the real scene about the whole logistics system, which is provide efficient visualization method of construction and improvement for the logistics center.

The teaching effects by this system are brought as following: (1) professional, it avoids empty Text teaching in designing the distribution center; (2) visualization, it avoid abstract teaching in facilities and equipment. It is so difficult for Students to imagine what the stacker, high-speed transport trolley like. But they recognize a variety of facilities and equipment through the software, and know how to use them; (3) it improves students' interest in animation display.

\section{Problems and Countermeasures in the process of applying in the Higher Vocational Logistics teaching}

Although, he use of modern educational technology is an inevitable trend in higher vocational logistics teaching, but it is still in the exploration stage. There are many problems which are worth paying attention to: the construction of modern teaching hardware facilities can not meet the demand, which need to be further improved and strengthened; the lack of high-quality teaching team; the lack of professional situation in the teaching practice when modern educational technology is applied; the lack of Cooperative enterprises in professional training. In order to solve these problems, personally I think we can do something in such three aspects:

\section{To strengthen the hardware construction of modern educational technology.}

Hardware facilities construction in the modern education technology is the foundation and prerequisite of the application of modern educational technology. It mainly includes two aspects in the logistics major. Firstly, strengthening the construction of teaching resources database, for example, encouraging teachers to develop and make multimedia courseware in order to sharing resources together and improving teaching efficiency; secondly, strengthening the construction of training base. The students master the utility of the logistics knowledge only through their own practice.

\section{To strengthen the teachers' own business training improves the professional skills training.}

To master the basic skills of applying modern education, in addition to know and be able to skillfully use a variety of modern educational technology, professional teachers need to design different teaching programs in the different teaching stage, considering the needs of teaching and 
personnel training. Nowadays, Modern educational technology teaching application from theory to practice is the primary task.

\section{To Strengthening the cooperation between colleges and enterprises.}

Because lack of professional situation in the teaching practice when modern educational technology is applied, so It is difficult to achieve the purpose of internship. Due to the lack training project and the corresponding training means developed in accordance with business process, it leads to the practice training virtual; the training course lack of real work task and the complete working process, students can only carry out some training in low level simply, loosely, partially, isolated, mechanically, statically.

\section{Summary}

More and more advanced information technology is used in the vocational logistics teaching fields. Although, there are many shortages which need to be improved, also we made some achievements Firstly. The ability to adapt of Graduates greatly enhanced, and they can meet the requirements of enterprises now. Teaching by modern educational technology, students are more easily winning when participate in the skills competition

\section{Literature References}

[1] Zhang Pengshun: Design of Virtual Reality Guide Training Room Based on the Modern Education Technology , $[\mathrm{J}]$. Frontier and Future Development of Information Technology in Medicine and Education,Lecture Notes in Electrical Engineering,Vol 269, 2014, pp 1221-1227.

[2] Canlong Wu,Shuying Zhan:Modern Education Technology and the Transformation of Teacher Role, Instrumentation, Measurement, Circuits and Systems Advances in Intelligent and Soft Computing, edtied by Tianbao Zhang, Vol 127, 2012, pp 185-190.

[3] Xue-Ping Chen,Modern information Technology Education and Change of Learning Style Research,Soft Computing in Information Communication Technology Advances in Intelligent and Soft Computing,Vol 158, 2012, pp 291-297.

[4] Dieter Uckelmann, The Role of Logistics Labs in Research and Higher Education, The Impact of Virtual, Remote, and Real Logistics Labs Communications in Computer and Information Science, Vol282, 2012, pp 1-12. 